\title{
HLA Phenotype Positive
}

National Cancer Institute

\section{Source}

National Cancer Institute. HLA Phenotype Positive. NCI Thesaurus. Code C154157.

An indication that a subject's human leukocyte antigen (HLA) complex expression profile is appropriate for inclusion in a study. 